
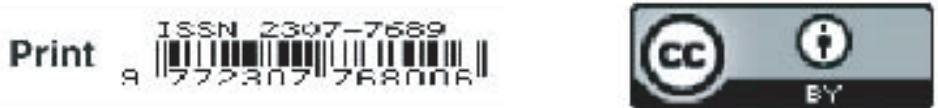

Online ISSN $2515-6054$

Mediscope

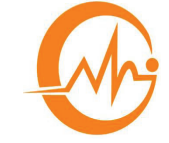

The Journal of GMC

\title{
Breast feeding practice among the rural women in selected villages of Dumuria upazilla, Khulna
}

\author{
R Zahan1, F Ferdaus², MA Rahman ${ }^{3}$, S Chowdhury4, E Zahan5, ME Islam6, MSH Mamun7
}

\begin{abstract}
The study attempted to describe the pattern of breast feeding practice among the rural women of Bangladesh with last child below 5 years of age living in the villages of Dumuria Upazilla. Due to small size of study group limited analysis were possible yet important variables such as the level of maternal education, age of starting complementary food, food used during weaning period, maternal knowledge of importance of colostrum and feeding of colostrum to the infant were considered. One of the important variables of the study was the level of the education of the respondents. As per the study, the majority $(41.06 \%)$ of the respondents passed secondary level. Maximum $90.0 \%$ mothers gave breast milk, $4.4 \%$ gave honey, $4.4 \%$ gave others and minimum $1.2 \%$ gave mixed food just after delivery. Majority $46 \%$ started breast feeding after 4 hours, $44.8 \%$ had within 1 hour, $6.8 \%$ after 1 st hours, $2.4 \%$ after 3 hours of delivery. Maximum $89.2 \%$ of the respondent fed exclusive breast feeding up to 1-2 months, $9.6 \%$ fed up to $3-4$ months, and $1.2 \%$ fed up to 5-6 months. Maximum $48.4 \%$ fed breast milk for $3-4$ months. Maximum $88.8 \%$ started complementary food within 6 months, $11.2 \%$ after 6 months.
\end{abstract}

Key words: Breast feeding, Rural women

\section{Introduction}

Every year millions of infant die throughout the world, mostly in developing countries. In Bangladesh, infant has continued a notable decline but it is still high in Bangladesh compared to other South Asian countries. Various factors including community factors also influence infant mortality and improvement of public health and family planning. At the community level, infant mortality might be influenced by specific cultures and customs. In Bangladesh, breastfeeding in rural areas appears to be shaped by the beliefs of a community ${ }^{1}$, which are further influenced by social, cultural, and economic factors. Initiation of breast feeding immediately after birth

\footnotetext{
1. Dr. Refat Zahan, Assistant Professor and Head, Department of Community Medicine, Ad-din Akij Medical College, Khulna

2. Dr. Farhana Ferdaus, Assistant Professor and Head, Department of Community Medicine, Khulna City Medical College, Khulna

3. Dr. Md. Abdur Rahman, Assistant Professor and Head, Department of Pharmacology and Therapeutics, Ad-din Akij Medical College, Khulna

4. Dr. Shahin Chowdhury, Ex. MPH Student, NIPSOM, Dhaka

5. Dr. Effat Zahan, Medical Officer, MSF

6. Dr. Md. Ehsanul Islam, Associate Professor and Head, Department of Biochemistry, Ad-din Akij Medical College, Khulna

7. Dr. Md. Shamsul Huda Mamun, Assistant Professor, Department of Forensic Medicine, Ad-din Akij Medical College, Khulna
} 
in Bangladesh preceded by so called prelacteal feeds. About $98 \%$ new born are traditionally fed "heating foods" such as honey, sugar water, or mustard oil with believe that these foods give strength and prevent colds during first few days of life and they also believed that honey makes babies' voice sweet. $^{2}$ Breast milk contains antibodies and live cells which protect infants from bacterial and viral pathogens and stimulates the infant's immune system. ${ }^{3}$ There are two main reasons for poor breastfeeding rates in our country: (i) a lack of support for mothers to initiate and sustain breastfeeding and (ii) secondly the erosion in breastfeeding practices by the violations of the national and international codes for the marketing of breast milk substitutes by the milk companies. Human milk provides advantages with strongest defense comes from colostrums, the substance produced in the first few days after birth, which provides the baby's first immunization. This works both before and during the time of feeding, the baby acquires active immunity through breast milk. The beneficial effects of breast milk depend on breastfeeding initiation, its duration, and the age at which the breast-feed child is weaned. ${ }^{4}$ We know from the Lancet 2003 Child survival series and from Karen Edmond's 2006 Pediatrics paper from Ghana $^{5}$ that universal optimal breastfeeding and complementary feeding are the most significant determinants of child mortality reduction in low and middle income countries. So, young child feeding practices are crucial for improving the health and nutritional status of children. Almost $96 \%$ of Bangladeshi children are breastfed for some period of time but only $9 \%$ initiate during the first hour of life and $48 \%$ within the first day of life. ${ }^{6}$ In Bangladesh, tragically the majority of fewer than 5 deaths $(80 \%)$ occur in the 1 st year of life, out of them, $45 \%$ from neonatal infection, 30\% from diarrheal, $18 \%$ from acute respiratory infection. The importance of exclusive breastfeeding and the immunological and nutritional values of breast milk have been demonstrated in deferent records. Breastfeeding is one of the most important determinants of birth spacing and prevention of childhood infections. ${ }^{7}$ Early initiation of breastfeeding helps mothers and child to get extra contact which foster bonding between mother and child from first hours of baby's life. ${ }^{8}$ Hence, the study with these relationships helps in orienting the breastfeeding promotional activities and for preventing a decline in initiation and duration of breastfeeding practices.

\section{Materials and methods}

A descriptive type of cross sectional study was carried out on breast feeding practices among rural women at the villages named Gutudia of Dumuria Upazilla from 30 January to 8th February, 2018.By purposive sampling technique a total number of 250 respondents having child less than 5 years old were included as sample. Before the collection of data, a structured questionnaire was prepared to explore the objective of the study. The contents were onset of breast-feeding, duration of breast-feeding, and weaning period. After collection, data were verified, edited for its consistency. The data were compiled, tabulated and processed in the computer according to the key variables. Data was processed and analyzed manually and by Computer. Data were presented by bar diagram and pie chart.

\section{Results}

Table 01: Distribution of respondents according toage $(n=250)$

\begin{tabular}{|c|c|c|}
\hline Age & $\begin{array}{c}\text { No of } \\
\text { respondents }\end{array}$ & $\begin{array}{c}\text { Percen- } \\
\text { tage }\end{array}$ \\
\hline 18-25 Years Old & 144 & $57.6 \%$ \\
\hline $26-33$ Years Old & 85 & $34.0 \%$ \\
\hline 34-41 Years old & 21 & $8.4 \%$ \\
\hline Total & 250 & $100.0 \%$ \\
\hline
\end{tabular}

It was revealed that majority of the respondents $57.6 \%$ were from $18-25$ years age group. Mean age of respondents was 22 $( \pm 5.18)$ years 
Figure 01: Distribution of respondents according to level of education $(n=250)$

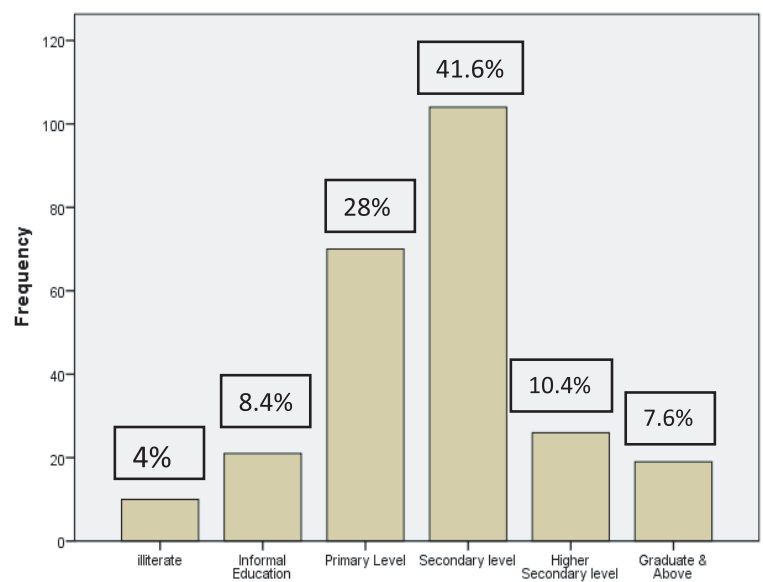

Figure 01 shows that majority $41.6 \%$ of the respondents were secondary level, $28 \%$ were primary level, $10.4 \%$ were higher secondary level, $8.4 \%$ were informal education, only $7.6 \%$ were graduate and $4 \%$ were illiterate.

\begin{tabular}{|c|c|c|}
\hline Age & $\begin{array}{c}\text { No of } \\
\text { respondents }\end{array}$ & Percentage \\
\hline $1-5$ years age child & 250 & $100.0 \%$ \\
\hline
\end{tabular}

Table 02: Shows that, the age of the children was within 1-5 years.

Figure 02: Distribution of mothers according to type of food given just after delivery $(n=250)$

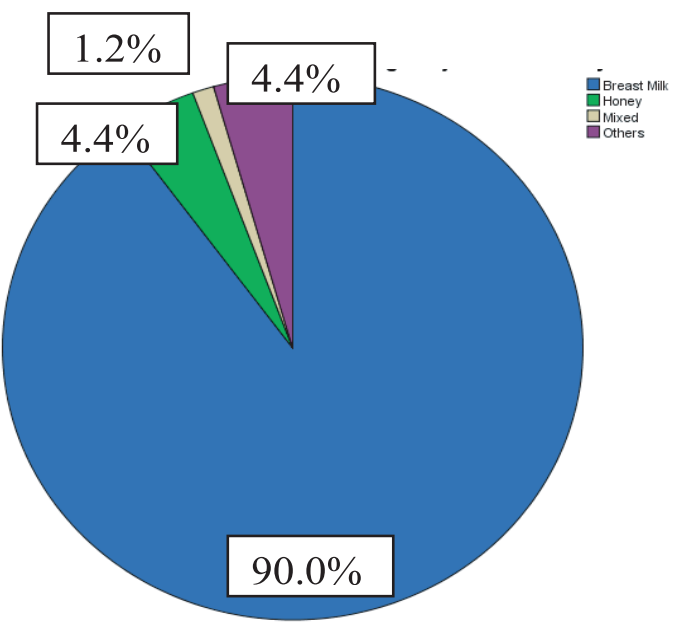

Figure 02: Shows that, the maximum $90.0 \%$ mothers gave breast milk, $4.4 \%$ gave honey, $4.4 \%$ gave others and minimum $1.2 \%$ gave mixed food
Table 03: Distribution of mothers according to starting-time of breast feeding just after delivery in hours $(n=250)$

\begin{tabular}{|l|c|c|}
\hline $\begin{array}{c}\text { Time to Start (in } \\
\text { hour) }\end{array}$ & $\begin{array}{c}\text { No of } \\
\text { respondents }\end{array}$ & Percentage \\
\hline Within $1^{\text {st }}$ hour & 112 & $44.8 \%$ \\
\hline After $1^{\text {st }}$ hour & 17 & $6.8 \%$ \\
\hline After 3 hour & 6 & $2.4 \%$ \\
\hline After 4 hour & 115 & $46.0 \%$ \\
\hline Total & $\mathbf{2 5 0}$ & $\mathbf{1 0 0 . 0 \%}$ \\
\hline
\end{tabular}

Table 03: Shows that the majority $46 \%$ started breast feeding after 4 hours, $44.8 \%$ had within 1 hour, $6.8 \%$ after 1 st hours, and $2.4 \%$ after 3 hours.

Figure 03: Distribution of mothers according to how many months they gave exclusive breast feeding $(n=250)$

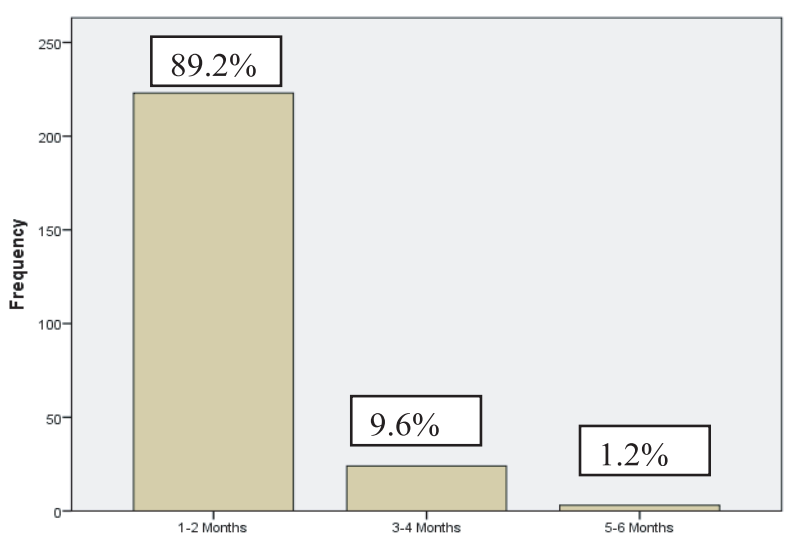

Figure 03: Shows that the maximum $89.2 \%$ of the respondent fed exclusive breast feeding up to $1-2$ months, $9.6 \%$ fed up to 3-4 months, $1.2 \%$ fed up to $5-6$ months.

Table 04: Distribution of mothers according to how many months they have given breast feeding $(n=250)$ :

\begin{tabular}{|c|c|c|}
\hline Months & $\begin{array}{c}\text { No of } \\
\text { respondents }\end{array}$ & Percent \% \\
\hline $1-2$ & 95 & $38.0 \%$ \\
\hline $3-4$ & 121 & $48.4 \%$ \\
\hline $5-6$ & 34 & $13.6 \%$ \\
\hline Total & 250 & $100.0 \%$ \\
\hline
\end{tabular}


Table 04: Shows that, the maximum (48.4\%) fed for 3-4 months, $38 \%$ fed for $1-2$ months and $13.6 \%$ fed for $5-6$ months.

Table 05: Distribution of respondents according to time of starting complementary foods in months $(n=250)$ :

\begin{tabular}{|l|c|c|}
\hline \multicolumn{1}{|c|}{ Time } & $\begin{array}{c}\text { No of } \\
\text { respondents }\end{array}$ & Percentage \\
\hline Within 6 months & 222 & $88.8 \%$ \\
\hline After 6 months & 28 & $11.2 \%$ \\
\hline Total & 250 & $100.0 \%$ \\
\hline
\end{tabular}

Table 05: Shows that, the maximum $88.8 \%$ started complementary food within 6 months, $11.2 \%$ after 6 months.

\section{Discussion}

The study attempted to describe the pattern of breast feeding practice among the rural women of Bangladesh with last child below 5 years of age living in the villages. This study revealed that majority of the respondents $57.6 \%$ were from 18-25 years age group. Mean age of respondents was $22( \pm 5.18)$ years. Majority of respondents were Muslims $76.4 \%$ \& the rest $23.6 \%$ were Hindu. Majority of respondents $92.8 \%$ were housewife, $4 \%$ were business, $1.2 \%$ were others, $0.8 \%$ were farmer, $0.8 \%$ were day labor, and $0.4 \%$ were service holder.

When the distribution of respondents according to type of food given just after delivery was considered, as per this study, it was found that $90 \%$ fed breast milk, $4.4 \%$ honey, $4.4 \%$ gave others and $1.2 \%$ gave mixed food. In a study of Dinajpur Medical College J 2010 Jan found that $34.9 \%$ of the women chose honey as pre-lacteal for their new born infant and $70.9 \%$ adapted breast milk. ${ }^{10}$

Delayed initiation of breast feeding is also common in Bangladesh. But, in this study, the majority $(46.0 \%)$ started breast feeding after 4 hours, $44.8 \%$ within one hour. The recent
DHS survey confirms $24 \%$ of the women initiated breast feeding within 1 hour and $83 \%$ one day after delivery. In Zeenath Rehana's study, 95 initiated within one hour, $48 \%$ within one day. ${ }^{13}$ Holman DJ et all in their survey found that $59 \%$ initiated breast feeding within 4 hours and $88 \%$ within 12 hours of delivery. ${ }^{14}$ A study conducted by ICDDR, B found out that $18 \%$ fed the newborn with breast milk within one hour and $23 \%$ within 2-3 hours. So the starting time of breast feeding is more or less similar.

ICDDR, B study showed that only $12 \%$ of the mothers were exclusively breast feeding their 0-5 month's old infant and 1\% of 9-12 months' infants which is slightly lower than the national recent survey according to which $4 \%$ of 10-12 months' infants were exclusively breast fed. ${ }^{11}$ One study showed that $34.5 \%$ of 0-3 month old infants were breast fed. ${ }^{12} \mathrm{DHS}$ 2004 showed that $38 \%$ infants aged 2-3 months were exclusively breast fed. As per this study the majority $(89.2 \%)$ of the respondents exclusively breast fed up to 1-2 months. While the distribution of respondents according to time of starting complementary food in months was recorded, as per this study it was found that $88.8 \%$ of mothers started it within 6 months, and $11.2 \%$ after 6 months of age. ICDDR, B study suggests that $11 \%$ of 1 month infants were started weaning food and $7.6 \%$ at 6 months of age. ${ }^{11}$

The type of food which was used for complementary food was Sagu/Barley/Suji for about $18.8 \%$, Khichuri $63.2 \%$, others $17.6 \%$ as per the study. In accordance to a survey conducted by Dinajpur Medical College they found that $43.5 \%$ mothers chose Suji as a primary weaning food and $36.1 \%$ chose Khichuri. ${ }^{10}$

A study of ICDDR, B stated that $90 \%$ of the mothers did not know that the colostrum should be the first and only food (for 6 months) for the baby. ${ }^{11}$ On the contrary according to this study only $4.4 \%$ did not 
know about the importance of colostrum and that it should be given to the child as his first food. Shameem Ahmed et al. in their study said only $12 \%$ women knew about the significance of colostrum. Study conducted by Das and Ahmed found that $81 \%$ women discarded colostrum as did not feed it to the infants whereas the study shows only $8.4 \%$ women did not feed her infants with colostrum and rest $91.59 \%$ did.

Our study shows that the Pattern of breast feeding Practice among the respondents of rural area of Bangladesh Correlates with the previous studies. The policy makers should provide proper health education about breast feeding. First of all, the practice of breast feeding has to be improved at the grassroot level.

\section{Conclusion}

Infants being the future generation of our society should be brought up healthy both physically and mentally for which breast feeding, weaning and rearing should be appropriate and in time. The results of this study shows that knowledge and practice regarding proper breast feeding practice among the rural women of Bangladesh is average while considering the fact that a lot other important variables were not considered and the study population was limited. Findings of the study suggest that it is important to raise awareness among the mothers, especially the rural women of Bangladesh, regarding proper breast feeding, including giving colostrums.

\section{Acknowledgement}

The authors gratefully acknowledge the technical support provided by Department of Community Medicine, Ad-din Akij Medical College, Khulna.

Conflict Of Interest: Nothing to declare.

\section{References}

1. Edmond KM, Zandoh C, Quigley MA, Amenga-Etego S, Owusu-Agyei S, Kirkwood BR. "Delayed breastfeeding initiation increases risk of neonatal mortality". Pediatrics 2006; 117: 380-386

2. Bangladesh Breastfeeding Foundation: protection, promotion and support breastfeeding, (http:/www.bbf-bd.org/home).

3. Iskandar MB, Costello C, Nasution Y. Initiation and duration of breastfeeding in Indonesia. Asia Pac Popul J. 1990; 5: 89-112. (Pub Med

4. Victora CG, Smith PG, Vaughan JP, Nobre LC, Lombardi C, Teixeira AM, et al. Evidence for protection against infant deaths from infections disease in Brazil. Lancet. 1987; 2:319-322.9Pub Med).

5. Arifeen S, Black RE, Antelman G, Baqui $A$, Caulfield L, Becker S. "exclusive breastfeeding reduces acute respiratory infection and diarrhea deaths among infants in Dhaka slums" Pediatrics. 2001;108:E67.

6. Dewey KG, Cohen RJ, Brown KH, Rivera LL. Effects of exclusive breastfeeding for four versus six months on maternal nutritional status and infant motor development: Results of two randomized trials in Honduras". J Nutr. 2001;131:262.

7. Mahalanabis D. "Breastfeeding and Vitamin A deficiency among children attending a diarrhea treatment center in Bangladesh; a case control study". BMJ. 1991;303:493-6.

8. Mitra SN, Ali MN, Islam S, Cross AR and Saha T. Bangladesh Demographic and Health Survey, 1993-1994. National Institute of Population Research and Training (NIPORT) Dhaka, Bangladesh.1994

9. N-Haque MJ, Rahman MM, Sarker SK, Ali MA, fakir M, R ahman MM, Islam MM $\mathrm{T}$-Infant Fuding Practice by the Rural Mothers of DinajpurDistict, V-Dinajpur Need Col J 2010 Jan; 3(1): 35-38] 
10. N-Shamem Ahmed, Ariful Islam, Sadia D Parveen, T-Infant Fuding Practicum in Rural Bangladesh: Plicy Implications, V-ICDDR, B Working Paper No.108

11. N-Meshram II, Al, KV, NVBG, T-Impact of feeding and breast feeding patterns on the nutritional status of infants in a district of Andhra Pradesh, India., V-Copyright 2012, NMJI
12. N-Zeenath Rahama, T-Exclusive breast feeding practices among Bangladeshi woman in Stockholm., V-KAROLINSKA INSTITTUTET., Department of Public Health Science Division of International Health Care Research (IHCAR) SE17176 STO CKHOLM, Sweden

13. N-Holman DJ, Grimes MA, T-Colostrum feeding behavior and initiation of breastfeeding in wral Bangladesh. V-J B iosoc Sic: 2001 Jan; 33 (1): 139-54 